\title{
PRESERVASI DIGITAL ARSIP NASKAH KUNO: Studi Kasus Preservasi Arsip di Badan Arsip dan Perpustakaan Provinsi Jawa Tengah
}

\author{
Nurrohmah Hidayah \\ Program Studi Interdisciplinary Islamic Studies Konsentrasi Ilmu Perpustakaan dan Informai \\ Universitas Islam Negeri Sunan Kalijaga Yogyakarta \\ Email: Nurrohmahhidayah1@gmail.com \\ Arina Faila Saufa \\ Program Studi Interdisciplinary Islamic Studies Konsentrasi Ilmu Perpustakaan dan Informai \\ Universitas Islam Negeri Sunan Kalijaga Yogyakarta \\ Email: Arinasaufan@gmail.com
}

\begin{abstract}
Abstrak
Penelitian ini berjudul "Preservasi Digital Arsip Naskah Kuno: studi kasus preservasi arsip di Badan Arsip dan Perpustakaan Provinsi Jawa Tengah.” Tujuan dari penelitian ini adalah untuk mengetahui proses dan kegiatan preservasi arsip digital naskah kuno yang ada di Barpusda Jawa Tengah. Metode penelitian yang digunakan adalah deskriptif kualitatif dengan metode pengumpulan data melalui observasi dan wawancara. Hasil penelitian yang didapatkan oleh peneliti adalah preservasi digital dilakukan pada koleksi mikrofilm, CD, dan hard disk eksternal. Barpusda Jateng melakukan kegiatan preservasi digital dengan 3 (tiga) strategi yaitu preservasi teknologi, penyegaran, dan migrasi. Preservasi teknologi yang dilakukan adalah dengan merawat hardware dan software yang digunakan untuk mengolah dan menyimpan materi digital. Penyegaran yang dilakukan adalah memindahkan materi digital dari satu media ke media lain, yaitu yang mulanya berbentuk mikrofilm diubah ke bentuk $\mathrm{CD}$, selanjutnya dipindah lagi ke hard disk eksternal. Migrasi yaitu pemindahan materi digital ke media elektronik yang lebih mutakhir, yaitu yang mulanya menggunakan software Windows harus dipindah ke software Macintosh karena menyesuaikan hardware yang disediakan. Kendala yang dihadapi dalam kegiatan prservasi digital ini di antaranya adalah kurangnya anggaran untuk kegiatan preservasi, tidak adanya kebijakan baku untuk pelaksanaan teknis preservasi digital sehingga mengharuskan membuat SOP sendiri, dan kurangnya Sumber Daya Manusia yang membantu sehingga membutuhkan waktu yang lebih lama dalam penyelesaiannya.
\end{abstract}

Kata Kunci: Arsip statis, Preservasi digital, Naskah Kuno

\begin{abstract}
Abstrak
Penelitian ini berjudul "Preservasi Digital Arsip Naskah Kuno: studi kasus preservasi arsip di Badan Arsip dan Perpustakaan Provinsi Jawa Tengah.” Tujuan dari penelitian ini adalah untuk mengetahui proses dan kegiatan preservasi arsip digital naskah kuno yang ada di Barpusda Jawa Tengah. Metode penelitian yang digunakan adalah deskriptif kualitatif dengan metode pengumpulan data melalui observasi dan wawancara. Hasil penelitian yang didapatkan oleh peneliti adalah preservasi digital dilakukan pada koleksi mikrofilm, CD, dan hard disk eksternal. Barpusda Jateng melakukan kegiatan preservasi digital dengan 3 (tiga) strategi yaitu preservasi teknologi, penyegaran, dan migrasi. Preservasi teknologi yang dilakukan adalah dengan merawat hardware dan software yang digunakan untuk mengolah dan menyimpan materi digital. Penyegaran yang dilakukan adalah memindahkan materi digital dari satu media ke media lain, yaitu yang mulanya berbentuk mikrofilm diubah ke bentuk $\mathrm{CD}$, selanjutnya dipindah lagi ke hard disk eksternal. Migrasi yaitu pemindahan materi digital ke media elektronik yang lebih mutakhir, yaitu yang mulanya menggunakan software Windows harus dipindah ke software Macintosh karena menyesuaikan hardware yang disediakan. Kendala yang dihadapi dalam kegiatan prservasi digital ini di antaranya adalah kurangnya anggaran untuk kegiatan preservasi, tidak adanya kebijakan baku untuk pelaksanaan teknis preservasi digital sehingga mengharuskan membuat SOP sendiri, dan kurangnya Sumber Daya Manusia yang membantu sehingga membutuhkan waktu yang lebih lama dalam penyelesaiannya.
\end{abstract}


Kata Kunci: Arsip statis, Preservasi digital, Naskah Kuno

\section{PENDAHULUAN}

Saat ini manusia hidup di era digital, di mana hampir seluruh kebutuhan informasi mereka dapat dengan mudah diakses melalui teknologi digital. Tetapi, seiring dengan berjalannya waktu, informasi dapat dituangkan dalam bentuk/media lainnya yaitu bentuk/media digital. Dokumen yang tidak berbentuk digital pun pada akhirnya harus didigitasi untuk menjaga agar informasi yang terkandung di dalamnya dapat terus dimanfaatkan dan digunakan untuk jangka waktu yang lama. Hal juga terjadi pada sumber informasi berupa arsip. Arsip harus selalu dijaga fisik maupun informasinya, mengingat peran dan fungsi arsip yang begitu penting bagi negara maupun pelaksanaan sebuah lembaga

Kegiatan menjaga fisik dan informasi arsip dapat dilakukan dengan melakukan kegiatan perawatan dan preservasi arsip. Hal ini diperlukan agar usia dari arsip dapat bertahan lebih lama. Menurut Barthos (2003: 314) preservasi adalah suatu kegiatan yang mencakup semua aspek usaha untuk melestarikan bahan pustaka dan arsip termasuk di dalamnya kebijakan pengolahan keuangan, ketenagaan metode, dan teknik penyimpanannya. Preservasi dilakukan pada bentuk asli bahan pustaka atau arsip yang dikoleksi oleh sebuah lembaga/perusahaan tertentu. Salah satunya adalah terhadap naskah kuno/manuskrip dan buku lama bernilai tinggi yang merupakan peninggalan dari generasi masa lampau.

Sebuah dokumen yang bentuknya rapuh seperti manuskrip/naskah kuno harus dialihmediakan atau diformat ulang untuk memperpanjang umur dari dokumen tersebut. Hal ini dapat dilakukan dengan mengubah bentuk atau format dokumen tersebut ke dalam bentuk digital. Setelah manuskrip/naskah kuno berubah menjadi dokumen yang berbentuk digital pun, sangat mungkin untuk terjadi kerusakan. Bahkan, ketika sebuah dokumen beralih menjadi dokumen digital, resiko kerusakannya justru semakin tinggi. Oleh sebab itu kegiatan preservasi juga perlu dilakukan terhadap dokumen-dokumen yang berbentuk digital. Kegiatan ini disebut juga kegiatan preservasi digital.

Menurut Pendit (2008: 248) Preservasi digital adalah, kegiatan terencana dan terkelola untuk memastikan agar bahan digital dapat dipakai selama mungkin. Preservasi digital juga meliputi upaya memastikan agar materi digital tidak bergantung pada kerusakan dan mencakup dari berbagai bentuk kegiatan mulai dari kegiatan sederhana menciptakan tiruan (copy) sampai kegiatan transformasi digital yang cenderung rumit. 
Badan Arsip dan Perpustakaan Daerah Provinsi Jawa Tengah (Barpusda) merupakan lembaga kearsipan yang bertugas menangani arsip dan sekaligus sebagai tempat bermuaranya arsip dari lembaga/perusahaan di Jawa Tengah. Selain arsip-arsip perusahaan/lembaga, Badan Arsip dan Perpustakaan Daerah Provinsi Jawa Tengah (Barpusda) juga menyimpan beberapa arsip Manuskrip Kuno yang sudah dialihmediakan ke bentuk digital, baik milik dari perorangan ataupun lembaga. Oleh karena itu, peneliti tertarik untuk meneliti kegiatan preservasi digital manuskrip/naskah kuno di Barpusda Jateng, dengan judul Preservasi Digital Terhadap Naskah Kuno/Manuskrip di Badan Arsip dan Perpustakaan Daerah Provinsi Jawa Tengah yang selanjutnya dilakukan dalam penelitian ini.

\section{TINJAUAN PUSTAKA}

\section{Arsip Statis}

Menurut Walne (1988: 128) arsip sebagai informasi terekam (recorded information) merupakan endapan informasi kegiatan administrasi/bukti transaksi pelaksanaan fungsi unitunit kerja yang terekam dalam berbagai media. Arsip statis merupakan arsip yang tidak dipergunakan secara langsung untuk perencanaan, pelaksanaa, penyelenggaraan kehidupan kebangsaan pada umumnya maupun utnuk penyelenggaraan sehari-hari administrasi negara.

Manurut Martono (1994: 28), arsip statis adalah arsip yang tidak berlau lagi bagi suatu organisasi atau lembaga yang dipelihara karena nilai yang berkelanjutan. Sementara menurut Undang-undang Nomor 43 tahun 2009 tentang kearsipan menjelaskan bahwa arsip statis adalah arsip yang dihasilkan oleh pencipta arsip karena memiliki nilai guna kesejarahan, telah habis masa retensinya, dan berketerangan dipermanenkan yang telah diverifikasi baik secara langsung maupun tidak langsung oleh Arsip Nasional Republik Indonesia dan/atau lembaga kearsipan. Dari beberapa pengertian tersebut dapat disimpulkan bahwa arsip statis adalah arsip yang tidak digunakan secara langsung dalam kegiatan kebangsaan karena mempunyai nilai kesejarahan dan harus dipermanenkan.

Arsip statis dapat dijadikan sebagai bukti autentik dan bukti sejarah yang terpercaya dari suatu kegiatan serta berfngsi sebagai memori kolektif yang menjadi simpul-simpul pemersatu bansga seiring dengan melemahnya nilai-nilai nasionalisme dan batas-batas wilayah bangsa pada era reformasi dan globalisasi.

Pelestarian dan peyempurnaan pemerintahan, institusi dan organisasi tergantung kepada kegiatan pelestarian dan pemanfaatan efisiensi akan arsip statis. Menurut SulistyoBasuki (2003: 10) fungsi arsip statis adalah: 
1. Sebagai memori perusahaan atau perorangan

2. Sebagai pembuktian

3. Sesuai dengan ketentuan perundang-undangan

4. Sebagai sumber penelitian

5. Keselamatan manusia

6. Kepentingan masyarakat

7. Kepentingan pendidikan dan hiburan

8. Memelihara aktivitas hubungan masyarakat

9. Kepentingan politik dan keamanan

10. Menelusur silsilah

11. Mempersiapkan sejarah peringatan lembaga atau perorangan

12. Memberikan sumbangan dalam pembinaan kepribadian nasional serta bermanfaat dalam melindungi warga, hak pribadi, dan lainnya.

\section{Preservasi Digital}

Dalam buku Harrod's Librarians Glossary, perservasi digital memiliki dua definisi yang pertama adalah penggunaan digital sebagai teknik prservasi, dan yang keduan adalah metode untuk menjaga agar materi digital tetap hidup sehingga dapat dimanfaatkan(Prytherch, 2005: 214). Sementara dalam buku Digital Preservation and Metadata: History, Theory, Practice istilah preservasi digital mengacu pada preservasi dari material atau koleksi yang diciptakan dalam format digital dan tidka pernah tersedia dalam bentuk tercetak atau analog dan menggunakan teknologi penggambaran atau rekaman untuk menciptakan salinan digital dari materi berformat analog untuk tujuan kemudahan akses dan pelestarian. Selain itu, materi digital baik yang tercipta secara digitakl maupun yang dikonversikan ke dalam bentuk digital sama-sama terancam kekeliruan dan kehancuran teknis (Lazinger, 2001: 18).

Menurut Peter Graham (1995), kegiatan preservasi untuk koleksi digital dapat diklasifikasikan melalui tiga kegiatan yaitu:

1. Pelestarian media penyimpanan

Pelestarian media penyimpanan memfokuskan pada kegiatan pelestarian media yang menyimpan informasi dalam pita, disk, CD-ROM dan lain-lain. kegiatan ini perlu dilakukan karena media penyimpanan ini merupakan akses yang harus dipelihara dan dijaga sedemikian rupa agar pengguna dapat menemukan kembali 
informasi yang ada di dalam media ini. Kegiatan ini dapat dilakukan dengan cara menyalin atau back up ke dalam media yang sejenis atau media dengan jenis yang berbeda.

2. Pelestarian teknologi

Sebagaimana kita ketahui, teknologi berkembang dengan sangat cepat. Bahkan dalam kurun waktu lima tahun sebuah software dapat mengeluarkan beberapa versi yang baru, lebih baik dan terus berkembang. hal ini juga berlaku pada hardware. Oleh sebab itu arsiparis harus berhati-hati terhadap keusangan teknologi yang digunakan untuk menyimpan dokumen digital atau untuk mengakses dokumen digital.

3. Pelestarian intelektual

Koleksi digital masih sangat rapuh dalam perlindungan hukum dan hak cipta, karena informasi digital dapat dengan mudah disalin tanpa adanya perbedaan. Walaupun sekarang sudah ada teknolog tanda tangan elektronik dan watermark namun hal ini masih merupakan sesuatu yang harus terus dikembangkan agar originalitas dalam informasi yang terkandung dalam dokumen digital dapat terus terjaga.

\section{METODE PENELITIAN}

Penelitian ini merupakan jenis penelitian kualitatif deskriptif dengan menggunakan metode studi kasus. Studi kasus merupakan kajian mendalam tentang peristiwa, lingkungan, dan situasi tertentu yang memungkinkan mengungkapkan atau memahami sesuatu (Sulityobasuki, 2006: 113). Dalam penelitian ini, peneliti menggunakan sample yang bertujuan (purposive sampling), dimana narasumber/informan dipilih berdasarkan tujuan tertentu. Informan yang ditentukan merupakan orang-orang yang memahami benar dan terlibat secara langsung dalam kegiatan preservasi digital di Ruang Preservasi Badan Arsip dan Perpustakaan Daerah Provinsi Jawa Tengah.

Peneliti memilih menggunakan metode wawancara dan observasi sebagai teknik pengumpulan data. Wawancara dilakukan kepada pengelola ruang preservasi digital sebagai informan dengan model wawancara campuran. Sedangkan dalam observasi dilakukan dengan terjun langsung melihat kegiatan preservasi digital untuk mengetahui kegiatan apa saja yang dilakukan dalam kegiatan preservasi digital terhadap naskah kuno/manuskrip berlangsung. Dengan metode penelitian tersebut, peneliti berharap dapat menjawab rumusan masalah peneliti yaitu, strategi kegiatan preservasi digital apa saja yang dilakukan oleh Badan Arsip 
dan Perpustakaan Provinsi Jawa Tengah terhadap Naskah kuno/manuskrip dan apa saja kendala-kendala yang ditemui pada saat kegiatan preservasi digital.

\section{PEMBAHASAN}

\section{Preservasi Digital di Ruang Preservasi Bapusda Jateng}

Kegiatan preservasi digital di Badan Arsip dan Perpustakaan Daerah Provinsi Jawa Tengah dilakukan secara terus-menerus setiap tahunnya sejak tahun 2006. Kegiatan preservasi digital dilakukan setelah proses digitalisasi selesai dilaksanakan. Kegiatan preservasi digital terhadap naskah kuno/manuskrip dilakukan terhadap arsip naskah kuno/manuskrip yang masih berbentuk kertas dan arsip naskah kuno yang sudah berbentuk mikrofilm. Untuk naskah yang masih berbentuk kertas, yang lebih diutamakan adalah naskah yang bentuknya sudah rapuh/rusak. Sedangkan untuk mikrofilm, diutamakan untuk naskah yang tidak terbaca gambar atau tulisannya di micro reader.

Kegiatan alih media (digitasi) dari bentuk fisik ke bentuk mikrofilm sudah dilakukan sejak tahun 1992, dan seiring dengan berjalannya waktu dan kemajuan teknologi, maka naskah yang sudah dimikrofilmkan juga harus dialihmediakan ke dalam bentuk CD. Ketika mokrofilm yang dibuat dialihmediakan ke dalam bentuk CD, maka mulai dari situ lah preservasi digital harus direncanakan. Karena seiring dengan kemajuan teknologi maka file digital yang tersimpan dalam CD harus dipindahkan lagi ke hard disk. Oleh sebab itu, kegiatan preservasi digital merupakan kegiatan yang berkelanjutan yang mengikuti kemajuan teknologi setiap masanya.

1. Proses digitasi

Sebelum melakukan kegiatan preservasi digital, naskah kuno/manuskrip yang tercipta dalam bentuk kertas terlebih dahulu dijadikan ke bentuk digital yang disebut juga dengan proses digitasi. Proses digitasi sendiri harus dilakukan melalui proses seleksi naskah untuk mengetahui arsip mana yang harus didahulukan. Koleksi yang didahulukan adalah koleksi naskah yang sudah rapuh dan rusak. Koleksi difoto dengan kamera lalu hasilnya dimasukkan ke dalam komputer yang kemudian diolah. Selain naskah yang sudah rusak, proses digitasi juga dilakukan terhadap naskah yang tersimpan di dalam CD yang dulunya adalah alih media dari mikrofilm. Naskah diseleksi mana yang tidak terbaca yang kemudian dilakukan digitasi ulang. Kebanyakan beberapa hasil CD hasil alih media mikrofilm tersebut sulit terbaca 
ketika dilihat dari komputer. Oleh sebab itu, naskah digital yang kondisi digitalnya kurang baik perlu didigitasi ulang agar dapat terbaca.

2. Pengolahan naskah setelah digitasi

Setelah dilakukan pemotretan terhadap naskah-naskah yang perlu didigitasi, maka langkah selanjutnya adalah mengolah gambar tersebut menggunakan komputer. Pemotretan yang dilakukan adalah semua halaman yang rusak sampai selesai. Setelah sisi kiri dan kanan dimasukkan ke dalam berkas yang berbeda, barulah dilakukan penggabungan file foto sisi kiri dan kanan naskah.

Setelah naskah digital digabungkan dan menjadi file naskah yang lengkap, maka format mereka adalah JPG karena merupakan hasil foto. Format ini ukurannya terlalu besar, sehingga harus diubah format menjadi PDF. Format PDF digunakan agar naskah tidah mudah untuk dimanipulasi dan tetap terlindungi seperti diberi footer atau password. File digital naskah diperkecil untuk memudahkan dalam penggunaan agar computer tidak cepat hang .

3. Kegiatan preservasi digital

Setelah kegiatan digitasi naskah selesai, maka tahap selanjutnya ada melakukan perawatan atau preservasi terhadap naskah tersebut. Dalam penelitian yang dilakukan melalui observasi dan wawancara, maka peneliti menemukan bahwa dalam kegiatan preservasi yang dilakukan Badan Arsip dan Perpustakaan Daerah Provinsi Jawa Tengah terhadap naskah kuno/manuskrip adalah:

a. Preservasi teknologi

Preservasi Teknologi adalah kegiatan perawatan secara seksama terhadap semua perangkat keras dan lunak yang dipakai untuk membaca, mengolah atau menjalankan sebuah materi digital tertentu. Materi dapat hilang atau mungkin tidak dapat dipakai lagi apabila mesin yang berupa hardware dan program yang berupa software kadaluwarsa (Pendit, 2008: 253). Badan Asip dan Perpustakaan Daerah Provinsi Jawa Tengah melakukan kegiatan preservasi teknologi terhadap hardware dan software yang digunakan untuk mengolah dan menyimpan naskah kuno/manuskrip. Hardware yang digunakan adalah komputer dengan sistem operasi Windows, sedangkan untuk software-nya adalah File Basic Renamer yang digunakan untuk pemberian nomor, nama, penggabungan file, pengecilan ukuran file, dan alih format dari JPG ke PDF. 
Preservasi teknologi yang dilakukan adalah terhadap naskah kuno/manuskrip yang sudah didigitasi. Naskah yang sudah didigitasi tersimpan di CD, mikrofilm, dan hard disk. Naskah yang tersimpan berjumlah sekitar 725 keping pada CD da, $1 \mathrm{CD}$ dapat memuat 20 judul, dan 250 roll pada mikrofilm, dan ada juga yang tersimpan di hard disk eksternal.

b. Penyegaran

Kegiatan penyegaran (refreshing) merupakan kegiatan yang paling mudah untuk diimplementasikan. Karena kegiatan ini tidak memerlukan banyak biaya, hanya saja menghabiskan banyak waktu mengingat banyaknya koleksi yang ada. Kegiatan penyegaran dilakukan pada koleksi naskah yang sudah tersimpan di dalam CD, disket, atau hard disk. Kegiatan preservasi ini penting karena sifat media penyimpanan yang semakin hari semakin berkembang. Untuk menghindari kehilangan data karena tempat penyimpanan yang tidak layak, maka perlu dilakukan penyegaran.

Kegiatan penyegaran ini memang membutuhkan waktu yang lama, karena harus menyalin dari CD yang jumlahnya 700-an ke dalam hard disk eksternal. Setelah itu naskah yang jumlahnya mencapai 300-an di dalam hard disk yang mencapai ukuran kurang lebih 885 gigabyte tersebut, harus disalin lagi ke hard disk eksternal lain milik pihak IT sebagi back-up. Kegiatan penyegaran juga dianggap efektif karena penyalinan data yang dilakukan bersifat keseluruhan tanpa mengubah konten data sedikit pun, sehingga setelah dipindahkan, data akan terlihat sama.

c. Migrasi

Kegiatan migrasi menurut Borghoff dan Rodig dalam Ramadhaniati (2012: 46) adalah pemindahan materi digital secara berkala dari satu konfigurasi hardware/software ke konfigurasi lainnya atau dari satu generasi komputer ke generasi yang lebih mutakhir. Kegiatan migrasi pada arsip digital yang dilakukan di Badan Arsip dan Perpustakaan Daerah Provinsi Jawa Tengah adalah arsip yang sudah didigitasi ke dalam bentuk hard disk eksternal. Koleksi tersebut merupakan koleksi yang mulanya berbentuk CD kemudian dipindahkan ke dalam hard disk eksternal. Selain itu, kegiatan migrasi dilakukan karena perubahan software yang awalnya menggunakan Windows dan sekarang menggunakan Macintosh. Karena 
software yang biasa digunakan dalam mengolah file digital di komputer Windows sekarang tidak bisa digunakan lagi pada Macintosh.

\section{Kendala Preservasi yang Dialami Barpusda Jateng}

Kegiatan preservasi digital terhadap manuskrip/naskah kuno yang dilakukan di Badan Arsip dan Perpustakaan Daerah Provinsi Jawa Tengah berdasarkan penelitian ini memiliki beberapa kendala yang menurut peniliti harus diperbaiki untuk mengoptimalkan kinerja preservasi digital tersebut. Kendala-kendala tersebut adalah:

\section{Kebijakan}

Setiap organisasi atau lembaga pasti memiliki kebijakan untuk mengatur seluruh kegiatan yang ada di organisasi tersebut. Kebijakan tersebut dibuat untuk memberikan batasan dan acuan dari kegiatan yang harus dilaksanakan agar sesuai dengan tujuan. Tidak adanya kebijakan baku mengenai preservasi digital mengakibatkan kesulitan dalam melakukan kegiatn preservasi digital pada setiap lembaga kearsipan. Akibatnya lembaga kearsipan (Barpusda Jateng) harus membuat Standar Operasional Prosedur (SOP) sendiri. Hal ini sangat disayangkan mengingat kegiatan preservasi yang sangat penting. Walaupun naskah kuno/manuskrip telah diperbaiki apabila rusak, tetapi kebijakan secara mendetail tidak ada. Hal ini menunjukkan bahwa kurangnya perhatian terhadap kegiatan preservasi digital.

2. Anggaran

Dalam melakukan setiap kegiatan dalam suatu lembaga atau organisasi pasti membutuhkan anggaran dana, termasuk kegiatan preservasi. Kegiatan preservasi digital dilakukan untuk menyelamatkan dan memperpanjang usia arsip yang berbentuk digital. kegiatan ini tentunya membutuhkan dana yang cukup banyak mengingat alat-alat yang digunakan adalah alat digital. ketersediaan dana juga akan berpengaruh pada kualitas dan pilihan strategi yang baik untuk preservasi digital.

3. Sumber Daya Manusia

Salah satu bagian yang penting dalam menjalankan suatu kegiatan adalah sumber daya manusia. Karena merekalah yang bertanggung jawab dalam kegiatan tersebut. Sumber daya manusia dalam hal preservasi digital ini adalah petugas atau pengelola ruang preservasi yang menjalankan semua kegiatan preservasi. Dari segi kuantitas SDM yang mengelola ruang preservasi tergolong kurang, karena yang 
bertugas hanya ada 3 (tiga) orang. Sedangkan arsip yang harus dikerjakan jumlahnya sangat banyak. Sehingga harusnya membutuhkan SDM yang banyak pula.

\section{KESIMPULAN}

Dari penelitian yang dilakukan serta menganalisis data-data yang terkumpul, maka peneliti dapat menarik kesimpulan, bahwa:

1. Preservasi digital terhadap naskah kuno/manuskrip dilakukan untuk materi digital berupa mikrofilm, CD, dan hard disk eksternal.

2. Badan arsip dan Perpustakaan Daerah Provinsi Jawa Tengah melakukan 3 (tiga) strategi preservasi digital terhadap naskah kuno/manuskrip yaitu Preservasi Teknologi, Penyegaran (refreshing), dan Migrasi atau Format Ulang.

3. Preservasi teknologi yang dilakukan adalah dengan merawat hardware dan software yang digunakan untuk mengolah dan menyimpan materi digital. Penyegaran yang dilakukan adalah memindahkan materi digital dari satu media ke media lain, yaitu yang mulanya berbentuk microfilm diubah ke bentuk $\mathrm{CD}$, selanjutnya dipindah lagi ke hard disk eksternal. Hal ini dilakukan karena mengikuti alat pembaca (hard ware dan software) yang terbaru. Kemudian Migrasi yaitu pemindahan materi digital ke media elektronil yang lebih mutakhir, dalam penelitian ini adalah yang mulanya menggunakan software Windows harus dipindah ke software Macintosh karena menyesuaikan hardware yang disediakan.

4. Kendala yang dihadapi dalam kegiatan prservasi digital ini diantaranya adalah kurangnya anggaran untuk kegiatan preservasi ini, tidak adanya kebijakan baku untuk pelaksanaan teknis preservasi digital sehingga mengharuskan membuat SOP sendiri, dan kurangnya Sumber Daya Manusia yang membantu sehingga membutuhkan waktu yang lebih lama dalam penyelesaiannya.

\section{DAFTAR PUSTAKA}

Amsyah, Zulkifli. 1991. Manajemen Kearsipan. Jakarta: Gramedia.

Apriani, Devi. 2010. Kegiatan Preservasi Arsip Foto di Museum Benteng Verdeburg Yogyakarta. Skripsi. FAI: Universitas Islam Negeri Sunan Kalijaga, Yogyakarta.

Barthos, Basir. 2003. Manajemen Kearsipan: untuk Lembaga Negara, Swasta, dan Perguruan Tinggi. Jakarta: Bumi Aksara. 
Borghoff, Uwe M. Et Mia. 2003. Long Term Preservaton for Digital Documents: principles and practices. Berlin: Springer.

Graham, Peter. 1995. Preserving the Digital Library dalam Long Term Preservation of Electronic Material a JISC/British Library Workshop 27-28 November

Lazinger, Susan S. 2001. Digital Preservation and Metadata: history, theory practice. Englewood: Libraries Unlimited.

Nelisa, Marta. 2013. "Pelestarian Naskah-naskah Kuno di Museum Nagari Adtyawarman Sumatera Barat”. Jurnal. FBS: Universitas Negeri Padang, Padang.

Pendit, Putu Laxman. 2008. Perpustakaan Digital: Dari A Sampai Z. Jakarta: Citra Karyakarsa Mandiri.

Prythrech, Raymond Jhon. 2005. Harrod's Librarians' Glossary and Refernce Book. Great Britain: MPG Books Ltd.

Ramadhaniati, Resti. 2010. Perawatan Buku Lama di Ruang Naskah Perpustakaan Universitas Indonesia. Skripsi. FIB: Universitas Indonesia, Depok.

Sulistyo-Basuki. 2006. Metode Penelitian. Jakarta: Wedatama Widya Sastra. 